\title{
Project Management Volume, Velocity, Variety: A Big Data Dynamics Approach
}

\author{
Fredrik Kockum ${ }^{a *} \&$ Nicholas Dacre ${ }^{a}$
}

\author{
${ }^{a}$ University of Southampton Business School, University of Southampton, Southampton, SO17 1BJ, UK \\ ${ }^{*}$ Corresponding Author: f.h.e.Kockum@soton.ac.uk
}

\begin{abstract}
The era of Big Data has provided business organisations opportunities to improve their management processes. This developmental paper is adopting a mixed-method research approach where qualitative data will underpin a quantitative questionnaire. The early insights are based on an initial eleven qualitative interviews and conceptualised in the following three statements: (i) Project practitioners need to increase their data literacy; (ii) Project practitioners are not utilising the available Big Data based on the 3 Vs; Volume, Velocity and Variety; (iii) Project practitioners need to utilise the structured available data to augment the decision-making process to represent the complex environment of Big Data, the study adopts Complexity Theory as a theoretical framework. When completed, the research will demonstrate the results through System Dynamics modelling.
\end{abstract}

Keywords: Project Management, Big Data, Volume, Velocity, Variety, 3 Vs, System Dynamics, Project Processes, Complexity Theory, Artificial Intelligence, AI.

\section{Suggested Citation}

Kockum, F., \& Dacre, N. (2021). Project Management Volume, Velocity, Variety: A Big Data Dynamics Approach. Advanced Project Management, 21(1). https://dx.doi.org/10.2139/ssrn.3813838

\section{Introduction}

Project management relationships with Data, Artificial Intelligence (AI) and relevant success factors for broader management is receiving increased attention through academic research, standardisation, and training (Anantatmula and Rad, 2018; Brookes et al., 2020; Dacre et al., 2020; Eggleton et al., 2020). The field of project management has emerged from operational research (Tavares, 2002) and can be defined as a temporary organisation (Bakker et al., 2016) or a temporary system (Söderlund and Sydow, 2019).

While project-based organisations have a significant influence on society, only $44 \%$ of organisations state they have the capability to deliver projects which meet the original project objective (KPMG et al., 2019). The request for project-based organisations is increasing as a result of a high demand for customised products and services (Lundin et al., 2015). "Pure customization" explains the concept when buying and selling parties have profound impact on the solution and the decision-making process (Lampel and Mintzberg, 1996).

The value of large data sets and Big Data relies on the organisation's ability to utilise this repository of information (Mikalef et al., 2018). Big Data and Big Data management have been used as 'buzz-words' during the last decade. One explanation to the technological advancements for Big Data management processes is 'Moore's law', which states the overall computing power doubles every second year. Dobre and Xhafa (2014) stated 2.5 quintillion bytes of data were created every day, considering a few years have passed since this statement, the current amount of created data can be considered to have increased in size. The project profession has not utilised the digital development of Big Data 
management processes. The initial findings in this study show there is a significant interest in this field among early adopters of project practitioners. In the reflection of the attention from industry, this research will study the combination of Big Data and Big Data management processes in projects. Research in conceptualising Big Data is necessary to overcome challenges in this area (Storey and Song, 2017).

The research implications of this study have potential to be both within the UK and globally. The research is currently in an early stage and the research question is of an exploratory nature: How can project managers leverage big data and big data management processes in projects?

\section{Research Context}

In a time of Big Data, project practitioners may utilise the flow of data to manage projects (Brookes et al., 2020; Dacre et al., 2020; Whyte et al., 2016). Both internal organisational data and external data can be applied and re-used to project life cycles (Whyte et al., 2016). Big Data has been defined consisting of 3 Vs, volume, velocity, and variety. Where volume refers to the amount of data available, velocity refers to the speed data is generated, and variety defines the types of data.

There have been suggestions to define big data by 5 Vs, adding veracity and value (White, 2012; Wamba et al., 2015). Further on, 7 Vs are suggested with valence and variability (Saggi and Jain, 2018). This research refers to the original mentioned 3 Vs.

Big data management is possible due to previous mentioned Moore's Law and the development of memory capacity (Zhang et al., 2015). This research has adopted Girard et al. (2015) approach of definition Big Data literacy, as a passive and active competence. Where the passive competence involves extracting and summarising Big Data in order to generate useful knowledge and develop experiences. Whereas the active role includes collecting, structuring, storing, and accessing Big Data.

Non-technical individuals as well as technical individuals may benefit from improving Big Data literacy (D'Ignazio and Bhargava, 2015). Big Data in an organisational environment, is based on an organisation to be an 'open-system' and that the data is available from all possible sources (Scholz, 2017).
This explains the complexity of Big Data and the choice of theoretical approach which is defined in the following section. Complex behaviour is emergent, dynamic, and non-linearity of variables (Geraldi et al., 2011). The literature shows decision-makers have difficulties to separate complex systems with complicated systems (Poli, 2013). A complicated system is able to be modelled, whereas a complex system is not capable to be modelled to its full extent (Poli, 2013). The research team acknowledges the limitations to model complex systems to its completion.

Complexity Theory (CT) has been demonstrated in the literature appropriate when analysing the impact of complexity in projects (Benbya and McKelvey, 2006). CT has been influenced by several sciences and has offered a paradigm-shift from traditional research assumptions within management and organisational studies (Allen et al., 2011). The authors of this study follow the study of complexity science, where social systems are defined as Complex Adaptive Systems (CAS) and non-linear (Cilliers, 2002).

The nature of CAS is an "open-system", where internal and external variables are included (Kerzner, 2017). Modelling the project-based environment through the concept of CAS provides the ability to give context to an organisation with a multi-project environment (Aritua et al., 2009).

There are several ways to model CAS. System Dynamics (SD) is an appropriate tool when attempting to understand a complex system (Forrester, 1994). SD has been proven to be suitable when modelling CAS and has been successfully applied in project management (Sterman, 1992; Lyneis and Ford, 2007).

\section{Methodology}

The chosen approach for the study will combine qualitative and quantitative research methods (Reynolds \& Dacre, 2019). The mixed-method approach is currently conducting semi-structured interviews with individuals in project roles with exposure to complex data in project environments. A qualitative method is chosen in order to understand, identify and analyse key areas from project practitioners (Basias and Pollalis, 2018). The sample for the qualitative research includes individuals from cross-sectional industries and are asked to give 
insights on the themes of the 3 Vs of Big Data and experience of managing Big Data processes in projects.

At this stage, meanwhile an iterative data analysis of the initial eleven interviews is underway, the research team is conducting supplementary interviews until reaching the aim of 25 interviews in total. To analyse the qualitative data, a Computer-Assisted Qualitative Data Analysis Software (CAQDAS) is used, more precisely QSR NVivo.

A Grounded Theory (GT) approach is adopted, which is based on an exploratory analysis of the qualitative data (Glaser et al., 1967). The combination of NVivo and GT is proven a suitable combination (Hutchison et al., 2010). NVivo is used for the rigour and transparency the software offers. GT will be used until theoretical saturation is reached.

The insights from the qualitative data will act as the foundation for the quantitative method which will take form of a questionnaire. This will likely include project practitioners internal and external to the APM community and reach around 150 participants.

This study will use System Dynamics (SD) as a tool to demonstrate the environment projects operate in. CT and SD share the common ground for complexity and non-linear environment of CAS. SD modelling gives the opportunity to study a "cause and effect" relationship of different actors, this has been demonstrated through the commonly occurring "rework cycle" in projects (Cooper, 1993). A thematic approach, where coding of the data reveals patterns of themes (Boyatzis, 1998) is employed when identifying the actors in the SD model.

\section{Empirical Findings}

The initial results indicate three themes: 1) Big Data Literacy, 2) Big Data Management and 3) Augmenting Decision Processes. The results presented are based on an initial analysis of the first eleven interviews. The semi-structured interview questions include themes of Big Data to provide insights of data volume, data velocity and data variety. Later, the final results will include the quantitative data and be analysed in relation to the theoretical approach of CT and modelled through SD.

The results incline to a tendency of Big Data-illiteracy among project decision-makers and project practitioners. This theme was found among a majority of the participants to explain why the project profession has not seen major impact from Big Data. Participant one stated:

"In five years, we hope the industry [construction] is comfortable in taking multibillion-dollar decisions using data rather than the opinion of a few"

An indirect comment was made by participant number two by explaining how the participant does not know how knowledgeable we [this specific organisation] are in this area. By lacking a reference point of the competitive market, project practitioners may find difficulties to define requirements for a competitive product or service.

Big Data 3 Vs Volume of data showed opposing views, where participant eleven mentioned the volume of data utilised by this specific organisation, we use a data set with around 200 million data points... from around 600 different projects.

Participant six confirmed the use of available data volume by commenting we only have clients with ten years of data. However, participant eight stated an opposed view and claimed the volume of Big Data is not desired, rather the relevant project data should be aimed for:

"I don't want Big Data, I want the right [correct] project data"

Data volume was the only factor within the $3 \mathrm{Vs}$ which showed opposed views. Velocity and variety showed little contrasting views. The velocity of data was shown to be done in stage processes rather than a continuous and in 'real-time'. Participant seven said we are of a stage/gate process... We face problem in our technical architecture to report in real-time. Participant nine commented by stating:

"The sooner we can use real time
reporting the better. Then we can
make decisions on real-time
information as opposed to
something that is two weeks out of
date, since the world moves very
quickly these days"

Varieties in data format was explained by participant eleven by stating: 
"Sometimes there is enough data but it is not structured in a way that enables us to use it"

Additional challenges for data variety was explained the limits in technology to read unstructured data, participant nine commented, our biggest challenge is free format text-data. In addition to the two mentioned themes, the initial results reveal the third theme of augmenting the decision-making process through the available structured data. This concept may enhance the idea of rational decision making based on facts, which Mintzberg et al. (2013) define as 'thinking first' decision model. Participant three stated the opportunity for the decision-making process on a senior level by standardising the data:

"The report that comes out is not generated by opinion... We get that standardisation we have never had before. From a senior team perspective, we can compare apples with apples"

The ability to increase the structured data is the ground pillar to increase the augmentation of Big Data and in decision-making processes.

\section{Conclusion}

Big Data has seen great attention recently (Brookes et al., 2020; Dacre et al., 2019; Dacre et al., 2020); industry and researchers are realising the importance of understanding new technology. The initial findings in this developing paper are aligned in a sense that each theme may impact the other in a project setting. The implication each theme may have can be demonstrated through the complex environment of projects, where a cause and effect relationship between variables may be demonstrated in CAS and SD. At this stage of the research, the impact of each theme within the CAS and the research implications are unknown. The later quantitative research aims to quantify this potential impact. The initial findings can be summarised by stating the volume of Big Data is available for project practitioners, however, it is often unstructured and therefore becomes unutilised. The velocity of Big Data is often collected at specific time periods. The Big Data literacy among project practitioners need to improve in order to utilise the data available. Depending on the success of these suggestions, the decision-making process has potential to be augmented. The research is cautious to draw early conclusions; however, the study demonstrates the following initial insights; (i) Project practitioners need to increase the literacy of Big Data. This may have an implication on the usage and awareness of the 3 Vs; (ii) Project practitioners are suggested to utilise the available Big Data based on the $3 \mathrm{Vs}$; volume, velocity, and variety. Through increasing the structured data, project practitioners may increase business value in additional areas of project processes. (iii) It is suggested that project practitioners utilise the structured available data in order to augment the decision-making process and to augment the decision-maker.

\section{References}

Allen, P., Maguire, S. \& Mckelvey, B. 2011. the Sage

Handbook of Complexity and Management, Sage

Publications.

Anantatmula, v. S. \& Rad, P. F. 2018. Role of Organizational Project Management Maturity Factors on Project Success. Engineering Management Journal, 30, 165-178.

https://doi.org/10.108o/10429247.2018.1458208

Aritua, B., Smith, N. J. \& Bower, D. 2009. Construction Client Multi-Projects - a Complex Adaptive Systems Perspective. International Journal of Project Management, 27, 72-79.

https://doi.org/10.1016/j.ijproman.2008.02.005

Bakker, R. M., Defillippi, R. J., Schwab, a. \& Sydoq, J. Temporary Organizing: Promises, Processes, Problems. Organization Studies, 37, 1703 -1719.

Basias, N. \& Pollalis, Y. 2018. Quantitative and Qualitative Research in Business \& Technology: Justifying a Suitable Research Methodology. Review of Integrative Business and Economics Research, 7, 91-105.

Benbya, H. \& Mckelvey, B. 2006. Toward a Complexity Theory of Information Systems Development. Information Technology \& People, 19, 12-34.

https://doi.org/10.1108/09593840610649952

Boyatzis, R. E. 1998. Transforming Qualitative Information: Thematic Analysis and Code Development, Sage.

Brookes, N., Lattuf Flores, L., Dyer, R., Stewart, I., Wang, K., \& Dacre, N. (2020). Project Data Analytics: The State of the Art and Science [APM Research]. Association for Project Management.

https://doi.org/10.5281/zenodo.4621177 
Brookes, N., Sage, D., Dainty, a., Locatelli, G. \& Whyte, J. 2017. an Island of Constancy in a Sea of Change: Rethinking Project Temporalities With Long-Term Megaprojects. International Journal of Project Management, 35, 1213-1224.

https://doi.org/10.1016/j.ijproman.2017.05.007

Cilliers, P. 2002. Complexity and Postmodernism: Understanding Complex Systems, Routledge.

Cooper, K. G. the Rework Cycle: Benchmarks for the Project Manager. 1993. Project Management Institute.

Dacre, N., Kockum, F., \& Senyo, PK. (2020). Transient Information Adaptation of Artificial Intelligence: Towards Sustainable Data Processes in Complex Projects. British Academy of Management, Manchester, UK. https://dx.doi.org/10.2139/ssrn.3813559

Dacre, N., Senyo, PK., \& Reynolds, D. (2019). Is an Engineering Project Management Degree Worth it? Developing Agile Digital Skills for Future Practice. Engineering Education Research Network, Coventry, UK. https://dx.doi.org/10.2139/ssrn.3812764

D'Ignazio, C. \& Bhargava, R. 2015. Approaches to Big Data Literacy. Bloomberg Data for Good Exchange Conference. New York.

Dobre, C. \& Xhafa, F. 2014. Intelligent Services for Big Data Science. Future Generation Computer Systems, 37, 267-281. https://doi.org/10.1016/j.future.2013.07.014

Eggleton, D., Dacre, N., Cantone, B., \& Gkogkidis, V. (2020). Redefining Success in Project Management [APM Research]. Association for Project Management. https://doi.org/10.5281/zenodo.4624779

Forrester, J. W. 1994. System Dynamics, Systems Thinking, and Soft or. System Dynamics Review, 10, 245256. https://doi.org/10.1002/sdr.4260100211

Geraldi, J., Maylor, H. \& Williams, T. 2011. Now, Let's Make It Really Complex (Complicated). International Journal of Operations \& Production Management, 31, 966-990. https://doi.org/10.1108/01443571111165848

Girard, J., Klein, D. \& Berg, K. 2015. Strategic Data-Based Wisdom in the Big Data Era, Hershey, USA, Igi Global.

Glaser, B. G., Strauss, a. L. \& Strutzel, E. 1967. The Discovery of Grounded Theory: Strategies for Qualitative Research New York Aldine de Gruyter. INC.
Hutchison, a. J., Johnston, L. H. \& Breckon, J. D. 2010. Using Qsr-Nvivo to Facilitate the Development of a Grounded Theory Project: An Account of a Worked Example. International Journal of Social Research Methodology, 13, 283-302.

https://doi.org/10.1080/13645570902996301

Kafouros, M. I., Buckley, P. J., Sharp, J. a. \& Wang, C. 2008. The Role of Internationalization in Explaining Innovation Performance. Technovation, 28, 63-74. https://doi.org/10.1016/j.technovation.2007.07.009

Kerzner, H. 2017. Project Management: A Systems Approach to Planning, Scheduling, and Controlling, John Wiley \& Sons.

Kmpg 2019. Driving Impact at Scale From Automation and AI. (Accessed 20 February 2020).

Lampel, J. \& Mintzberg, H. 1996. Customizing Customization. Sloan Management Review, 38, 21-30.

Lundin, R. a., Arvidsson, N., Brady, T., Ekstedt, E. \& Midler, C. 2015. Managing and Working in Project Society, Cambridge University Press.

Lyneis, J. M. \& Ford, D. N. 2007. System Dynamics Applied to Project Management: A Survey, Assessment, and Directions for Future Research. System Dynamics Review: The Journal of the System Dynamics Society, 23, 157-189. https://doi.org/10.1002/sdr.377

Mikalef, P., Pappas, I. O., Krogstie, J. \& Giannakos, M. 2018. Big Data Analytics Capabilities: A Systematic Literature Review and Research Agenda. Information Systems and E-Business Management, 16, 547-578. https://doi.org/10.1007/s10257-017-0362-y

Mintzberg, H., Ahlastrand, B. \& Lampel, J. 2013. Management? It's Not What You Think!, United Kingdom, Pearson.

Poli, R. 2013. a Note on the Difference Between Complicated and Complex Social Systems. Cadmus, 2, 142.

Reynolds, D., \& Dacre, N. (2019). Interdisciplinary Research Methodologies in Engineering Education Research. Engineering Education Research Network, Coventry, UK. https://dx.doi.org/10.2139/ssrn.3812769

Saggi, M. K. \& Jain, S. 2018. a Survey Towards an Integration of Big Data Analytics to Big Insights for ValueCreation. Information Processing \& Management, 54, 758-790. https://doi.org/10.1016/j.ipm.2018.01.010 
Scholz, T. M. 2017. Big Data in Organizations and the Role of Human Resource Management: A Complex Systems Theory-Based Conceptualization, Frankfurt a. M.: Peter Lang International Academic Publishers.

Söderlund, J. \& Sydow, J. 2019. Projects and Institutions: Towards Understanding Their Mutual Constitution and Dynamics. International Journal of Project Management, 37, 259-268.

https://doi.org/10.1016/j.ijproman.2019.01.001

Sterman, J. D. 1992. System Dynamics Modeling for Project Management. Sloan School of Management, MIT.

Storey, v. C. \& Song, I.-Y. 2017. Big Data Technologies and Management: What Conceptual Modeling Can Do. Data \& Knowledge Engineering, 108, 50-67.

https://doi.org/10.1016/j.datak.2017.01.001

Tavares, L. v. 2002. a Review of the Contribution of Operational Research to Project Management. European Journal of Operational Research, 136, 1-18.

https://doi.org/10.1016/So377-2217(01)ooo97-2
Wamba, S. F., Akter, S., Edwards, a., Chopin, G. \& Gnanzou, D. 2015. How 'Big Data' Can Make Big Impact: Findings From a Systematic Review and a Longitudinal Case Study. International Journal of Production Economics, 165, 234-246.

https://doi.org/10.1016/j.ijpe.2014.12.031

White, M. 2012. Digital Workplaces: Vision and Reality. Business Information Review, 29, 205-214. https://doi.org/10.1177\%2Fo266382112470412

Whyte, J., Stasis, a. \& Lindkvist, C. 2016. Managing Change in the Delivery of Complex Projects: Configuration Management, Asset Information and 'Big Data'.

International Journal of Project Management, 34, 339351. https://doi.org/10.1016/j.ijproman.2015.02.006

Zhang, H., Chen, G., Ooi, B. C., Tan, K. \& Zhang, M. 2015. in-Memory Big Data Management and Processing: A Survey. Ieee Transactions on Knowledge and Data Engineering, 27, 1920-1948. https://doi.org/10.1109/TKDE.2015.2427795

Advanced Project Management | APROM www.southampton.ac.uk/aprom

The Advanced Project Management research series accepts working conceptual and empirical papers, literature reviews, development papers, technical papers, case studies, and general reviews. Papers of a qualitative, quantitative, or mixed methods nature are welcome, including highly novel research approaches where relevant. Authors retain copyright of their work. The title page should include: Title; Author Name(s); Institution Affiliation(s); Contact Email Address(es); Abstract; and Keywords. Submit your paper as a Word or PDF file to: aprom@southampton.ac.uk 